\title{
Plasma vitronectin is reduced in patients with myasthenia gravis: Diagnostic and pathophysiological potential
}

Journal of Circulating Biomarkers Volume 8: $1-9$ (C) The Author(s) 2019 Article reuse guidelines: sagepub.com/journals-permissions DOI: $10.1177 / 1849454419875912$ journals.sagepub.com/home/cbx (\$)SAGE

\author{
Antonio Junior Lepedda' ${ }^{\oplus}$, Giovanni Andrea Deiana ${ }^{2}$, \\ Omar Lobina', Gabriele Nieddu', Paola Baldinu', \\ Pierina De Muro', Francesca Andreetta ${ }^{3}$, Elia Sechi', \\ Giannina Arru², Davide Giacomo Corda ${ }^{2}$, Gian Pietro Sechi', \\ and Marilena Formato'
}

\begin{abstract}
Myasthenia gravis (MG) is an autoimmune disease leading to varying degrees of skeletal muscle weakness. It is caused by specific antibodies directed against definite components in the postsynaptic membrane at the neuromuscular junction (NMJ), such as the acetylcholine receptor (AChR) and the muscle-specific kinase (MUSK) receptor. In clinical practice, MG patients may be classified into three main subgroups based on the occurrence of serum autoantibodies directed against AChR or MUSK receptor or antibody-negative. As the MG subgroups differ in terms of clinical characteristics, disease pathogenesis, prognosis, and response to therapies, they could benefit from targeted treatment as well as the detection of other possible disease biomarkers. We performed proteomics on plasma fractions enriched in low-abundance proteins to identify potential biomarkers according to different autoimmune responses. By this approach, we evidenced a significant reduction of vitronectin in MG patients compared to healthy controls, irrespective of the autoantibodies NMJ target. The obtained results were validated by mono- and two-dimensional Western blotting analysis. Vitronectin is a multifunctional glycoprotein involved in the regulation of several pathophysiological processes, including complement-dependent immune response, coagulation, fibrinolysis, pericellular proteolysis, cell attachment, and spreading. The pathophysiological significance of the reduction of plasma vitronectin in MG patients has yet to be fully elucidated. It could be related either to a possible deposition of vitronectin at NMJ to counteract the complement-mediated muscle damage at this level or to a parallel variation of this glycoprotein in the muscle extracellular matrix with secondary induced alteration in clustering of $\mathrm{AChRs}$ at NMJ, as it occurs with variation in concentrations of agrin, another extracellular matrix component. The clinical value of measuring plasma vitronectin has yet to be defined. According to present findings, significantly lower plasma values of this glycoprotein might be indicative of an impaired complement-dependent immune response.
\end{abstract}

\section{Keywords}

Myasthenia gravis, autoimmunity, vitronectin, proteomics, biomarkers

Date received: 19 February 2019; accepted: 18 August 2019

\footnotetext{
'Department of Biomedical Sciences, University of Sassari, Viale San Pietro, Sassari, Italy

${ }^{2}$ Department of Medical, Surgical and Experimental Sciences, University of Sassari, Viale San Pietro, Sassari, Italy

${ }^{3}$ Diagnostic Laboratory of Neuroimmunolgy, U.O. Neurologia IV, I.R.C.C.S. Fondazione Istituto Neurologico “C. Besta”, Milano, Italy

Corresponding Author:

Marilena Formato, Dipartimento di Scienze Biomediche, University of Sassari, Viale San Pietro 43, 07100 Sassari, Italy. Email: formato@uniss.it
} 


\section{Introduction}

Myasthenia gravis (MG) is a chronic autoimmune neuromuscular disease characterized by varying degrees of weakness of the skeletal muscles caused by autoantibodies against some proteins of the neuromuscular junction (NMJ) involved in nerve signal transduction. ${ }^{1,2}$

According to the autoantibodies target, ${ }^{3-5}$ patients can be subgrouped in anti-muscle acetylcholine receptor antibody positive $\left(\mathrm{AChRAb}^{+}\right)$, with a prevalence of about $80 \%$ (70\% of cases detectable with routine assays and 5-10\% with more-sensitive, cell-based assays); anti-musclespecific kinase antibody positive $\left(\mathrm{MuSKAb}^{+}\right)$, with a prevalence up to $10 \%$ (more frequent in the Mediterranean area than Northern Europe, possibly owing to a combination of genetic and environmental factors); and anti-lowdensity lipoprotein receptor-related protein 4 antibody positive $\left(\mathrm{LRP}^{+}\right)$, detected in $1-5 \%$ of patients with $\mathrm{MG}$ of any type and in 7-33\% of MG patients without AChR and MuSK antibodies. There is also a minority of patients called double seronegative (DSN) patients, because they do not have detectable antibodies against AChR or MuSK. Other known autoantibodies targets are agrin, titin, the voltage-gated $\mathrm{K}^{+}$channel $\mathrm{K}_{\mathrm{V}} 1.4$, ryanodine receptor, collagen $\mathrm{Q}$, and cortactin. Finally, there is a further subtype of patients in which the target of the autoimmune response is not known yet.

Three main mechanisms underline the loss of functional AChRs directly resulting in the destruction of muscle end plate: the binding of divalent antibodies causing crosslinking of AChRs and accelerated internalization and degradation of the receptor; direct sterical blocking of acetylcholine binding sites; complement-mediated lysis of postsynaptic membrane resulting in functional impairment of AChRs and reduction of voltage-gated $\mathrm{Na}^{+}$channels number, leading to increased action potential threshold. ${ }^{6}$

MuSK protein is essential for NMJ formation and agrininduced AChR clustering. ${ }^{7}$ MuSK antibodies have been demonstrated to inhibit AChR clustering. ${ }^{8}$ Moreover, they are able to cause experimental autoimmune $\mathrm{MG}^{9,10}$

Recently, LRP4 has been identified as a new autoantigen in DSN patients. ${ }^{11,12}$ LRP4 acts as a receptor for agrin $^{13}$ and is required for agrin-induced activation of MuSK, AChR clustering, and NMJ formation. ${ }^{14}$ Actually, no commercial tests for LRP4 antibodies are available and standardization of clinical setting has not been achieved yet. ${ }^{3}$

MG patients differ in terms of clinical characteristics, disease pathogenesis, prognosis, and response to therapies ${ }^{3}$ accounting for the significant variability among MG subgroups. However, targeted therapeutic and prognostic studies are rare. In this respect, identification of new disease biomarkers could help in tailoring specific treatments for clinical management of this pathology.

The aim of this study was to identify potential plasma biomarkers of $\mathrm{MG}$ in patients with different autoimmune responses, by applying two-dimensional electrophoresis
(2-DE) analysis coupled with mass spectrometry (MS) to a plasma fraction enriched in low-abundance proteins. We applied a recently developed technology, based on hexapeptide combinatorial ligand libraries, to increase the low-abundance proteins concentration with simultaneous minimal capture of the high abundance species. ${ }^{15}$

\section{Materials and methods}

\section{Sample collection}

Forty-two consecutive patients diagnosed with generalized MG referred to the Neuroimmunological Laboratory of the Neurological Clinic (Department of Medical, Surgical and Experimental Sciences, University of Sassari) for autoantibody testing were recruited in the period from January 2016 to December 2016. Clinical features or severity of disease were evaluated according to the Myasthenia Gravis Foundation of America (MGFA) clinical classification. ${ }^{16}$ In particular, the diagnosis of MG was clinically based on fluctuating muscle weakness, worsening with repetitive activities while improving with resting, clearly responding to acetylcholinesterase inhibitors in the absence of other alternative diagnoses with or without findings of impairment of neuromuscular transmission on single fiber EMG and on the repetitive stimulation test of motor nerves. All patients were under symptomatic therapy with pyridostigmine, an inhibitor of acetylcholinesterase, at the recruitment. Furthermore, some of them were under immunosuppressive therapy with corticosteroids and/or azathioprine, as reported in Table 1. Twenty-four healthy volunteers, matched for age and sex with patients, were enrolled as controls. Informed consent was obtained before enrolment. Exclusion criteria were the presence of renal, hematological, liver, or other associated chronic autoimmune diseases. Peripheral venous blood samples were drawn into plastic syringes, under sterile conditions, and immediately transferred into tubes containing ethylenediamine tetraacetic acid.K3-salt (K3 EDTA). Plasma was separated from whole blood by centrifugation at room temperature at $1000 \times g$ for $10 \mathrm{~min}$ and stored at $-80^{\circ} \mathrm{C}$ until assayed. Anti-AChR and anti-MuSK antibodies were measured either by radioimmunoassay kit (RSR Limited, Avenue Park, Pentwyn, Cardiff, UK) or Enzyme Linked Immunosorbent Assay (ELISA) kit (RSR Limited). LRP4 autoantibodies were detected by a cellbased assay with HEK293 cells transfected with human LRP4 fused to green fluorescent protein. Human IgG were detected with Cy3-conjugated anti-human IgG antibody. Cells were examined on laser scanning confocal microscope system (Nikon Instruments Europe B.V).

Of 42 patients, 18 were $\mathrm{AChRAb}^{+}$, among which 2 patients were also found positive for anti-LRP4 antibodies, 8 patients were $\mathrm{MuSKAb}^{+}$, and 16 were negative for both anti AChR and MusK antibodies and referred to as DSN, 2 of which were positive for anti-LRP4 antibodies.

All study participants gave informed written consent to the study. Institutional review board approval was obtained 
Table I. Characteristics of 42 MG patients and relative abundances of plasma vitronectin obtained by two-dimensional electrophoresis analysis.

\begin{tabular}{|c|c|c|c|c|c|c|}
\hline & Patients $^{\mathrm{a}}$ & Age & Gender & MGFA clinical classification & Immunosuppressive therapy & Vitronectin (relative abundance) \\
\hline \multirow[t]{18}{*}{$\mathrm{AChRAb}^{+}$} & I & 65 & $\mathrm{~F}$ & IIB & Corticosteroids & 456.19 \\
\hline & 2 & 61 & $\mathrm{~F}$ & IIA & - & $26,970.9$ \\
\hline & 3 & 64 & $\mathrm{~F}$ & IIA & Corticosteroids, azathioprine & 4249 \\
\hline & 4 & 85 & $M$ & IIA & DSN & 343.65 \\
\hline & 5 & 80 & $\mathrm{~F}$ & IIIB & - & 7479.01 \\
\hline & 6 & 91 & $\mathrm{~F}$ & IIIB & - & $78 \mid 2.01$ \\
\hline & 7 & 79 & $\mathrm{~F}$ & IIA & Azathioprine & 299.87 \\
\hline & 8 & 80 & $\mathrm{~F}$ & IVA & - & 907.01 \\
\hline & 9 & 50 & $\mathrm{~F}$ & IIIB & - & 8500.03 \\
\hline & 10 & 40 & $\mathrm{~F}$ & IVB & Corticosteroids & 3484.04 \\
\hline & 11 & 51 & $M$ & IIIB & - & 387.54 \\
\hline & 12 & 61 & $\mathrm{~F}$ & IIIB & Corticosteroids, azathioprine & 6030.09 \\
\hline & 13 & 43 & $\mathrm{~F}$ & IIIA & Corticosteroids, azathioprine & $16,526.1$ \\
\hline & 14 & 83 & $M$ & II & - & 4273.02 \\
\hline & 15 & 53 & $\mathrm{~F}$ & IIIA & Corticosteroids, azathioprine & 7659 \\
\hline & 16 & 84 & $\mathrm{~F}$ & IIB & Corticosteroids, azathioprine & 7852.04 \\
\hline & $17^{*}$ & 89 & $M$ & II & - & 586.07 \\
\hline & $18^{*}$ & 67 & $\mathrm{~F}$ & IIIB & - & 1860 \\
\hline \multirow[t]{8}{*}{$\mathrm{MuSKAb}^{+}$} & 19 & 84 & $\mathrm{~F}$ & IV & Corticosteroids & $15,019.9$ \\
\hline & 20 & 52 & $\mathrm{~F}$ & IIB & Corticosteroids & 1488 \\
\hline & 21 & 50 & $\mathrm{~F}$ & IIIB & Corticosteroids, azathioprine & $|7,97| .6$ \\
\hline & 22 & 49 & $\mathrm{~F}$ & IIIB & Corticosteroids, azathioprine & 1739.08 \\
\hline & 23 & 79 & $\mathrm{~F}$ & IIIB & - & 940.08 \\
\hline & 24 & 45 & $\mathrm{~F}$ & IIIB & - & 2023.05 \\
\hline & 25 & 82 & $\mathrm{~F}$ & IIIB & - & 2680.05 \\
\hline & 26 & 68 & M & IIB & Corticosteroids & 5560 \\
\hline \multirow[t]{16}{*}{ DSN } & 27 & 50 & $M$ & II & - & 8363.08 \\
\hline & 28 & 63 & $\mathrm{~F}$ & IIIB & - & 1783.04 \\
\hline & 29 & 63 & $\mathrm{~F}$ & $\| \mathrm{A}$ & Corticosteroids & 5334.09 \\
\hline & 30 & 69 & $\mathrm{~F}$ & $\| \mathrm{A}$ & - & 2627.02 \\
\hline & 31 & 89 & M & IIB & - & 5180.03 \\
\hline & 32 & 69 & $M$ & IIB & Corticosteroids, azathioprine & $|28| .0 \mid$ \\
\hline & 33 & 91 & $M$ & IIIA & - & 566.1 \\
\hline & 34 & 59 & $M$ & IIA & - & 313.06 \\
\hline & 35 & 47 & M & IIA & - & $12,596.4$ \\
\hline & 36 & 83 & $\mathrm{~F}$ & IIB & Azathioprine & $|357.0|$ \\
\hline & 37 & 28 & $\mathrm{~F}$ & $\| \mathrm{A}$ & & $13,856.5$ \\
\hline & 38 & 64 & $M$ & IIIB & Corticosteroids, azathioprine & 2726.02 \\
\hline & 39 & 60 & $\mathrm{~F}$ & $\| \mathrm{A}$ & - & $13,573.2$ \\
\hline & 40 & 91 & $M$ & IIB & - & 6443.07 \\
\hline & $4 I^{* *}$ & 47 & $\mathrm{~F}$ & $\| \mathrm{A}$ & Corticosteroids, azathioprine & 7620.02 \\
\hline & $42 * *$ & 76 & $M$ & IIB & Corticosteroids, azathioprine & 1661.04 \\
\hline
\end{tabular}

MG: myasthenia gravis; $\mathrm{AChRAb}^{+}$: acetylcholine receptor antibody positive; MGFA: Myasthenia Gravis Foundation of America; LRP4Ab ${ }^{+}$lipoprotein receptor-related protein 4 antibody positive; $\mathrm{MUSKA}^{+}$: anti-muscle-specific kinase antibody positive.

${ }^{a}$ All patients were under symptomatic therapy with pyridostigmine, an inhibitor of acetylcholinesterase, at the recruitment.

$* \mathrm{AChRAb}^{+} / \mathrm{LRP} 4 \mathrm{Ab} \mathrm{b}^{+}$patients.

$* *$ DSN/LRP4Ab ${ }^{+}$patients.

(protocol no. 2195/2/CE, 09/12/2015). The study was conducted in accordance with the ethical principles of the current Declaration of Helsinki.

\section{Plasma low-abundance proteins enrichment}

To reduce the very high dynamic range of protein concentration in plasma and to perform differential protein expression analysis of the lower expressed fraction,
ProteoMiner ${ }^{\mathrm{TM}}$ enrichment kit (Bio-Rad, Hercules, California, USA), which exploits nonspecific interactions with a large, highly diverse bead-based library of combinatorial peptide ligands, was used according to the manufacturer's instructions with slight modifications. ${ }^{17}$ The hexapeptides baits are potentially able to interact with any protein present in a complex proteome. The system works in large overloading conditions in which abundant proteins saturate their ligand sites on beads, whereas trace proteins are 
enriched, thus reducing the dynamic protein concentration range. ${ }^{15}$ It means that, by means of this process, the most abundant plasma proteins, including Apo AI, are "equalized" and, therefore, they do not differ among enriched samples.

Briefly, $1 \mathrm{ml}$ plasma sample was incubated with the functionalized beads for $2 \mathrm{~h}$ at room temperature followed by two consecutive elution steps with $150 \mu \mathrm{L}$ of an elution buffer containing 2\% 3-[(3-Cholamidopropyl)dimethylammonio]-1-propanesulfonate (CHAPS), $8 \mathrm{M}$ urea, and 5\% acetic acid. Then, eluate was concentrated and dialyzed against a buffer containing $8 \mathrm{M}$ urea and $4 \%$ CHAPS using Amicon ultra- $0.5 \mathrm{~mL}$ centrifugal filter units (Millipore, Billerica, Massachusetts, USA). Protein concentration was determined using DC Protein Assay Kit (Bio-Rad), according to the manufacturer's instructions, using bovine serum albumin as the standard. Proteins were stored at $-20^{\circ} \mathrm{C}$ until analysis.

\section{Differential protein expression analysis}

Two-dimensional electrophoresis (2-DE) was performed as previously described. ${ }^{17-19}$ Briefly, $300 \mu \mathrm{g}$ of proteins was applied to $70 \mathrm{~mm}$ Immobilized $\mathrm{pH}$ Gradient (IPG) strips (pH 3-10, Bio-Rad) for $6 \mathrm{~h}$ by rehydration loading at $20^{\circ} \mathrm{C}$ and subsequently focused at $50 \mu \mathrm{A} / \mathrm{IPG}$ strip for $22 \mathrm{kVh}$ at $20^{\circ} \mathrm{C}$ in a protean Isoelectric Focusing (IEF) cell (Bio$\mathrm{Rad})$. Following IEF, proteins were in-gel reduced by incubating IPG strips with a $50 \mathrm{mM}$ Tris buffer containing $6 \mathrm{M}$ urea, $30 \%$ glycerol (v/v), 3\% sodium dodecyl sulfate (SDS) $(\mathrm{w} / \mathrm{v})$, and $1 \%$ dithiothreitol (DTT) (w/v), followed by ingel alkylation, using the same solution containing $2.5 \%$ iodoacetamide (w/v) in place of DTT. Each step was performed keeping strips under continuous shaking for $15 \mathrm{~min}$. Then IPG strips were sealed, with $0.5 \%$ low melting point agarose $(\mathrm{w} / \mathrm{v})$ in SDS running buffer at the top of second dimension gels $\left(8 \times 7 \times 0.1 \mathrm{~cm}^{3}\right)$. Sodium Dodecyl Sulphate - PolyAcrylamide Gel Electrophoresis (SDS-PAGE) was carried out on $12 \% \mathrm{~T}, 3 \% \mathrm{C}$ polyacrylamide gels for 15 min at $50 \mathrm{~V}$ followed by $90 \mathrm{~min}$ at $150 \mathrm{~V}$ in a mini-protean tetra cell (Bio-Rad). Gels were then fixed in $30 \%$ ethanol $(\mathrm{v} / \mathrm{v})$ and $2 \%$ phosphoric acid $(\mathrm{v} / \mathrm{v})$ solution for $1 \mathrm{~h}$, washed twice in $2 \%$ phosphoric acid (v/v) solution for $10 \mathrm{~min}$, equilibrated in $18 \%$ ethanol $(\mathrm{v} / \mathrm{v}), 2 \%$ phosphoric acid (v/ $\mathrm{v})$, and $15 \%$ ammonium sulfate (w/v) solution for $30 \mathrm{~min}$, and then stained in the same solution added with $0.02 \%$ Coomassie Brilliant Blue G250 (w/v) for $48 \mathrm{~h}$. Gel images were acquired using GS800 calibrated densitometer (Bio$\mathrm{Rad})$ at $36.3 \mu \mathrm{m}$ resolution. Image analyses were performed using PDQuest 2-D analysis software V8.0.1 (Bio-Rad). 2-DE proteome maps were normalized by assigning to each detected spot a relative value corresponding to the ratio of single spot volume to the volume of all spots in the gel after background subtraction.

\section{In-gel digestion and Matrix-Assisted Laser Desorption/lonization-Time Of Flight Mass Spectrometry (MALDI-TOF MS) analysis}

Protein identification was obtained by a MS analysis service (Nurex S.r.l., Sassari, Italy). Spots of interest were excised from gels with sterile pipette tips, destained with a solution containing $2.5 \mathrm{mM} \mathrm{NH}_{4} \mathrm{HCO}_{3}$ and $50 \%$ acetonitrile (v/v), dehydrated with $100 \%$ acetonitrile, and dried at room temperature before proteolytic treatment. Tryptic digestion was performed by incubating dried spots in 5 $\mathrm{mM} \mathrm{NH} \mathrm{HCO}_{3}$ buffer containing $10 \mathrm{ng} / \mu \mathrm{L}$ trypsin overnight at $37^{\circ} \mathrm{C}$. The resulting peptides were mixed with an equal volume of $\alpha$-cyano-4-hydroxycinnamic acid saturated solution $(40 \%$ acetonitrile $(\mathrm{v} / \mathrm{v})$ and $0.1 \%$ trifluoroacetic acid $(\mathrm{v} / \mathrm{v}))$ and applied as a microcrystalline thin film onto a stainless steel 96-spot MALDI target. Mass analyses were performed using a MALDI microMX-mass-spectrometer (Waters, Manchester, UK), according to the tuning procedures suggested by the manufacturer. Peak lists were generated using Protein Lynx Global Server v.2.2.5 (Waters) and searched against the Swiss-Prot human database (version 57.4) using Mascot (http://www.matrixscience.com). Research parameters included taxa (Homo sapiens), trypsin digest, monoisotopic peptide masses, iodoacetamide modifications, one missed cleavage by trypsin, and a mass deviation of $50 \mathrm{ppm}$. Only protein identifications with significant Mascot scores $(p<0.05)$ were taken into consideration.

\section{Western blotting analysis}

Western blotting (WB) analysis was performed as previously described ${ }^{17-19} ; 5 \mu \mathrm{g}$ of low-expressed plasma proteins-enriched fraction and an equivalent of $0.25 \mu \mathrm{L}$ of plasma from untreated samples were resolved by SDSPAGE on $5 \% \mathrm{~T}, 3 \% \mathrm{C}$ stacking gel, and $12 \% \mathrm{~T}, 3 \% \mathrm{C}$ polyacrylamide separating gel. With regard to $2-\mathrm{DE} \mathrm{WB}$ analysis, $50 \mu \mathrm{g}$ of pooled enriched fractions and $1 \mu \mathrm{L}$ of pooled plasma samples from each MG patients subgroup and from control group were resolved as described above. Subsequently, resolved proteins were electroblotted onto Hybond-P PVDF membranes (GE Healthcare, Uppsala, Sweden) at $250 \mathrm{~mA}$ for $1.5 \mathrm{~h}$. Afterward, membranes were incubated with blocking solution (PBS, $0.1 \%$ Tween-20, $3 \%$ nonfat dry milk) for $1 \mathrm{~h}$ at room temperature, followed by overnight incubation at $4^{\circ} \mathrm{C}$, either with a rabbit monoclonal anti-Vitronectin (clone EP873Y, ab45139, Millipore), diluted 1:20,000 with blocking solution, or with a goat polyclonal anti-apolipoprotein AI antibody (AB740, Millipore), diluted 1:4,000, for data normalization. Then, after 30-min washing (PBS, 0.1\% Tween-20), membranes were incubated with anti-rabbit (dilution 1:5,000, Bio-Rad) or anti-goat (dilution 1:5,000, Bio-Rad) horseradish peroxidase (HRP)-conjugated secondary antibody solution for 1 
(a)

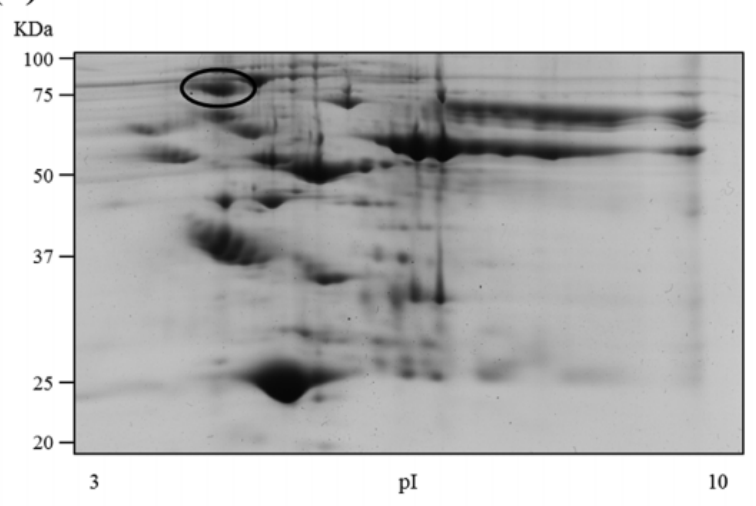

(c)

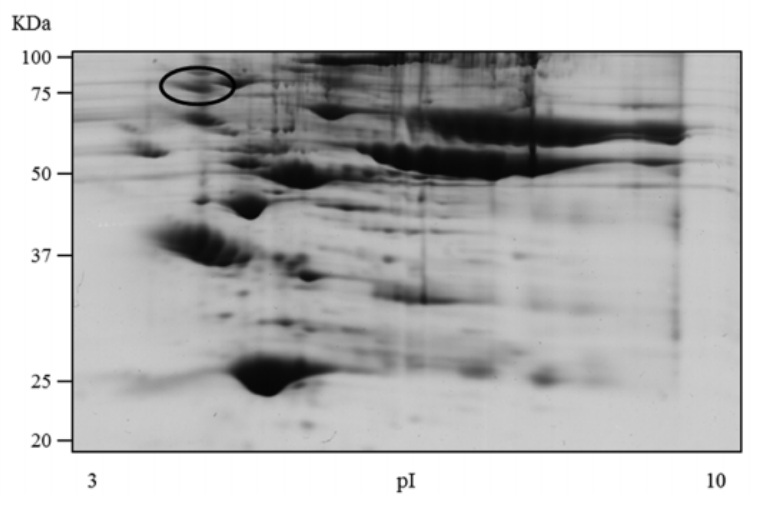

(b)

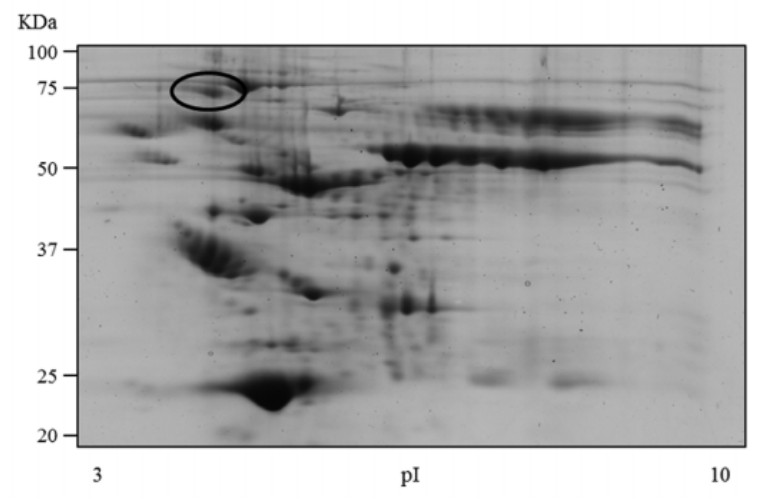

(d)

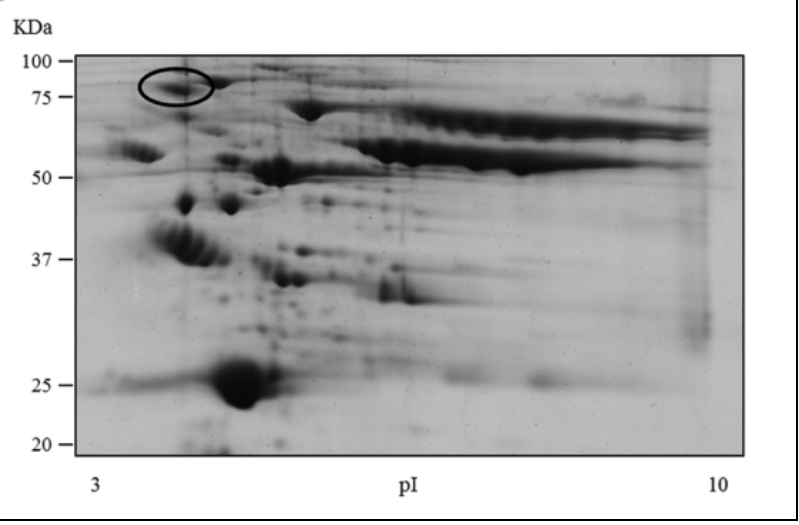

Figure I. Representative 2-DE maps of plasma low-abundance proteins-enriched fractions from healthy controls (a), AChRAb ${ }^{+}$MG patients (b), MuSKAb ${ }^{+}$MG patients (c), and DSN MG patients (d) after mass compatible Coomassie Brillant Blue G-250 staining. Molecular weight standards (all blue prestained protein standards, Bio Rad) were run alongside focused strips in the second dimension. Circled spots train, corresponding to vitronectin, was differentially expressed between MG patients and controls. 2-DE: twodimensional electrophoresis; $A C h R A b^{+}$: acetylcholine receptor antibody positive; MuSKAb ${ }^{+}$: anti-muscle-specific kinase antibody positive; MG: myasthenia gravis.

$\mathrm{h}$ at room temperature. Following further membrane washing, proteins were revealed by enhanced chemiluminescence (Amersham ECL Prime Western Blotting Detection Reagent; GE Healthcare) using ChemiDoc XRS System (Bio-Rad) for data acquisition. Densitometric analysis was performed using Quantity One 4.6.3 software (Bio-Rad).

\section{Statistical analysis}

Student's $t$-test analysis was performed to evaluate variations in protein expression levels among MG subgroups and healthy controls. Statistical significance was set at $p<0.05$.

\section{Results}

Patients with clinical diagnosis of $\mathrm{MG}$ were classified into three subgroups, $\mathrm{AChRAb}^{+}, \mathrm{MuSKAb}^{+}$, and DSN patients, based on the presence of antibodies against different NMJ targets (Table 1). Among them, four patients were also positive for anti-LRP4 antibodies. As the presence of high-abundance proteins in plasma samples (e.g. albumin and $\mathrm{IgG}$ ) makes the detection of medium- and lowabundance proteins extremely challenging, ${ }^{15}$ we performed an enrichment in low-expressed proteins using hexapeptide ligand libraries. Following sample elution, an additional dialysis step was necessary to remove acetic acid from the elution buffer and optimize isoelectric focusing/separation in the first dimension of 2-DE. ${ }^{17}$ This approach led to a reduction of the most abundant plasma proteins $(85 \%$ of albumin was depleted) and to an increase of the less represented ones, with a total number of protein spots detected of about 2.4 times higher in treated samples, enabling the differential expression analysis of the less represented proteins (Figure 1). Comparative 2-DE analysis of lowabundance proteins enriched plasma samples, using PDQuest 2-D analysis software V8.0.1, coupled with MALDI-TOF MS, allowed us to identify vitronectin as differentially expressed between MG patients and healthy controls (UniProtKB/Swiss-Prot accession number: P04004.1). In particular, vitronectin was significantly reduced in all $\mathrm{MG}$ patients subgroups as compared to healthy controls $\left(-54 \%\right.$ in $\mathrm{AChRAb}^{+}, p=0.012 ;-58 \%$ 


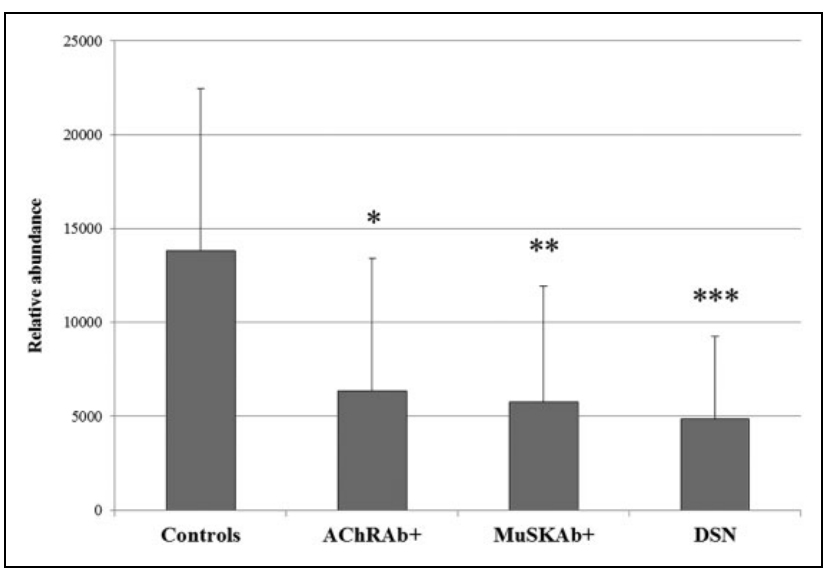

Figure 2. Bar chart reporting relative abundances of vitronectin obtained by 2-DE maps image analysis of enriched plasma samples from healthy controls, $\mathrm{AChRAb}^{+} \mathrm{MG}$ patients, MuSKAb ${ }^{+} \mathrm{MG}$ patients, and DSN MG patients. Data are reported as mean \pm SD. $* \mathrm{AChRAb}^{+}$versus controls, $-54 \%, p$ value $=0.012 ; * *$ MuSKAb ${ }^{+}$ versus controls, $-58 \%, p$ value $=0.020$; $* *$ DSN versus controls, $-65 \%$, $p$ value $=0.002$. 2-DE: two-dimensional electrophoresis; $\mathrm{AChRAb}^{+}$: acetylcholine receptor antibody positive; MG:

Myasthenia gravis; MuSKAb ${ }^{+}$anti-muscle-specific kinase antibody positive; SD: standard deviation. in $\mathrm{MuSKAb}^{+}, p=0.010 ;-65 \%$ in DSN, $p=0.002$ ) (Figure 2), but no significant difference was evidenced in vitronectin expression among MG subgroups. Furthermore, no association between vitronectin expression and severity of disease, according to MGFA Clinical Classification, or immunosuppressive therapies was found (Table 1). One-dimensional WB analysis, confirming 2-DE findings, showed a significant down-expression of vitronectin in all myasthenic patients (Figure 3) being $-39 \%$ in $\mathrm{AChRAb}^{+}$ $(p<0.001),-40 \%$ in $\mathrm{MuSKAb}^{+}(p<0.001),-43 \%$ in DSN $(p<0.001)$ enriched samples, $-57 \%$ in AChRAb ${ }^{+}$ $(p<0.001),-70 \%$ in $\mathrm{MuSKAb}^{+}(p<0.001)$, and $-67 \%$ in DSN $(p<0.001)$ whole plasma samples. These reductions were observed in MG patients irrespective of their autoimmune response. Apo AI expression was used for WB data normalization. Further confirmation came from twodimensional WB analysis on pooled plasma samples both as a whole and after enrichment treatment (Figure 4).

\section{Discussion}

MG is an autoimmune disorder mainly mediated by autoantibodies against postsynaptic membrane proteins at the

\section{(a)}

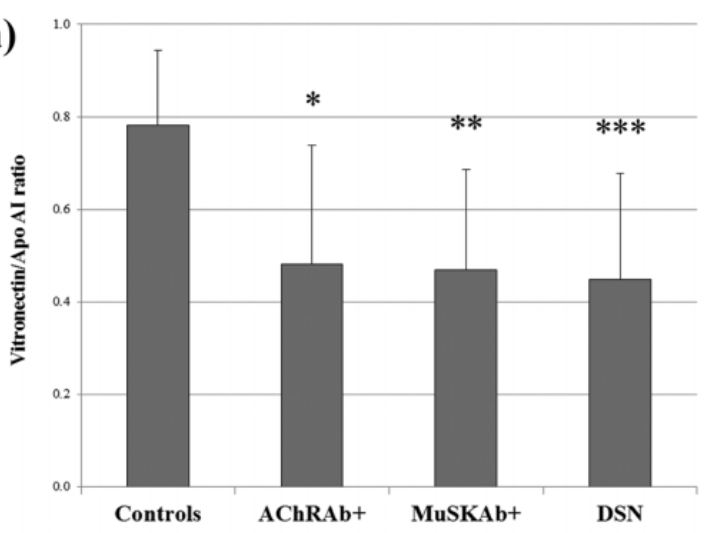

(c)

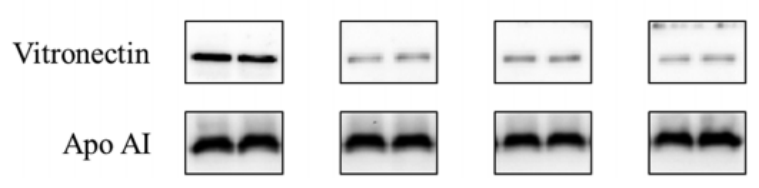

(b)

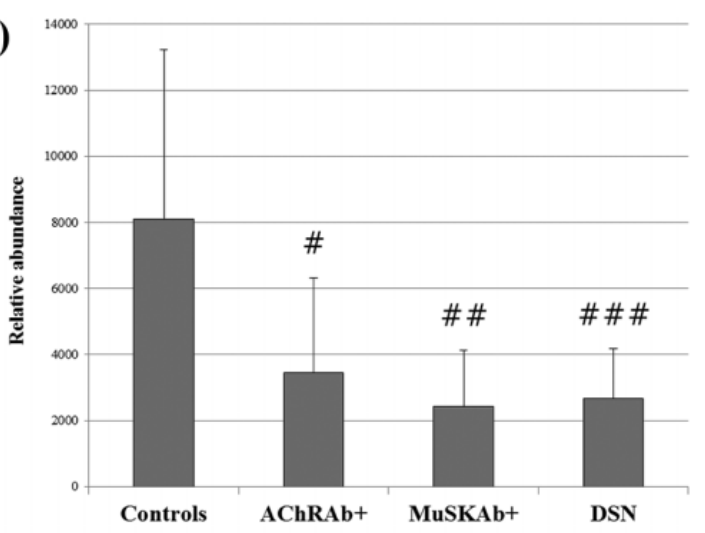

(d)

Vitronectin - -
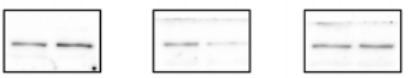

Figure 3. WB analysis of Vitronectin expression in both enriched ((a) and (c)) and whole ((b) and (d)) plasma samples from healthy controls, $\mathrm{AChRAb}^{+} \mathrm{MG}$ patients, MuSKAb ${ }^{+} \mathrm{MG}$ patients and DSN MG patients. (a) Bar chart reporting relative abundances of Vitronectin in enriched fractions normalized for apolipoprotein Al levels, obtained by image analysis of WB profiles. (b) Bar chart reporting relative abundances of Vitronectin in whole plasma samples obtained by image analysis of WB profiles. (c) Mono-dimensional WB profiles of both Vitronectin and apolipoprotein Al in enriched plasma fractions. (d) Mono-dimensional WB profiles of Vitronectin in whole plasma samples. Data are reported as mean $\pm \mathrm{SD}$. ${ }^{*} \mathrm{AChRAb}{ }^{+}$vs Controls, $-39 \%$, $p$ value $<0.00 \mathrm{I}$; ** MuSKAb ${ }^{+}$vs Controls, $-40 \%, p$ value $<0.00$ I; ***DSN vs Controls, $-39 \%$, $p$ value $<0.00$ I; ${ }^{*} \mathrm{AChRAb}{ }^{+}$vs Controls, $-57 \%, p$ value $<0.00 \mathrm{I}$; ${ }^{\#} \mathrm{MuSKAb}^{+}$vs Controls, $-70 \%, p$ value $<0.001$; DSN vs Controls, $-67 \%$, $p$ value $<0.001$. 
(a)

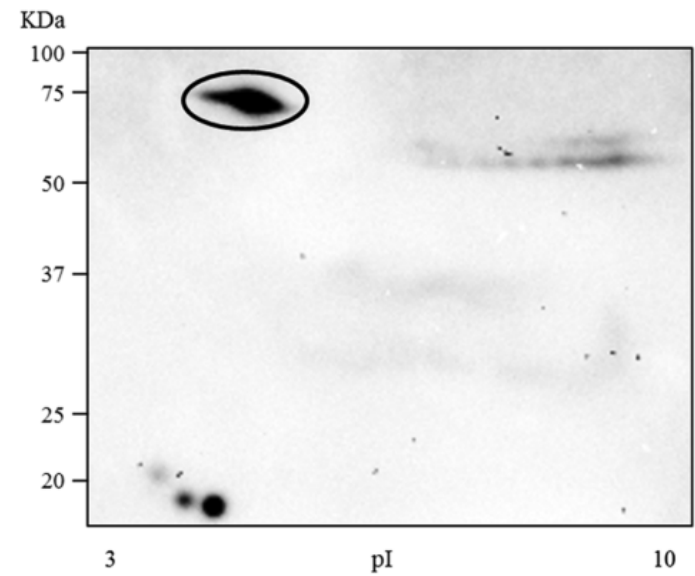

(c)

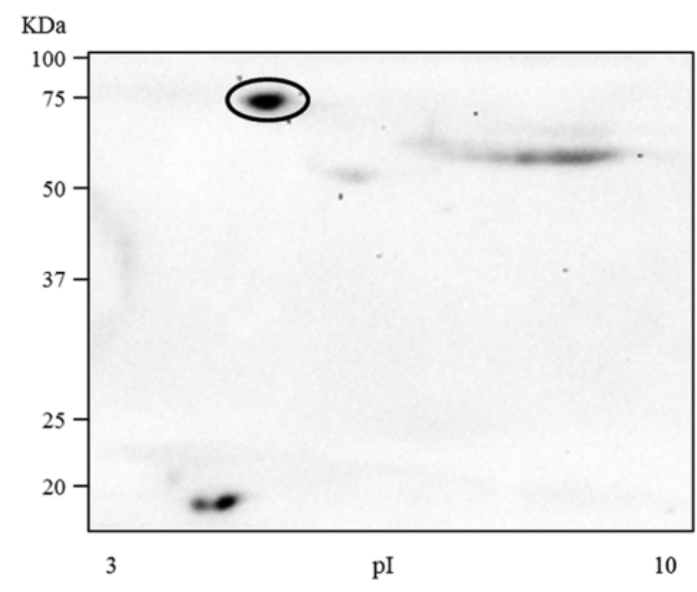

(b)

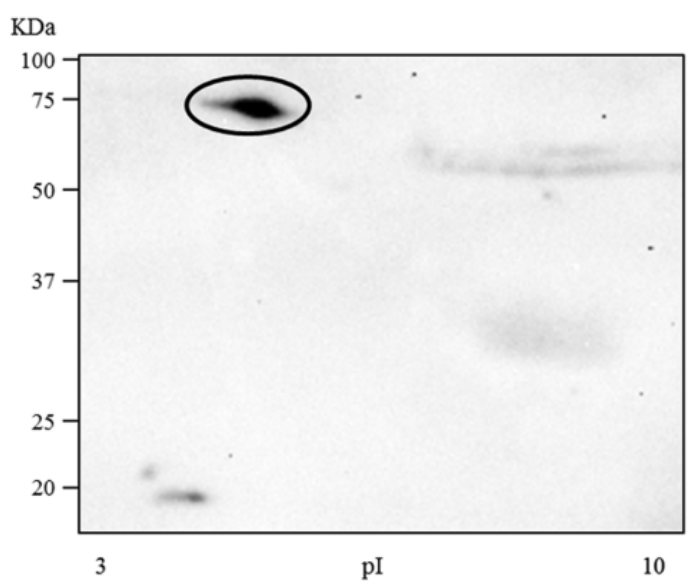

(d)

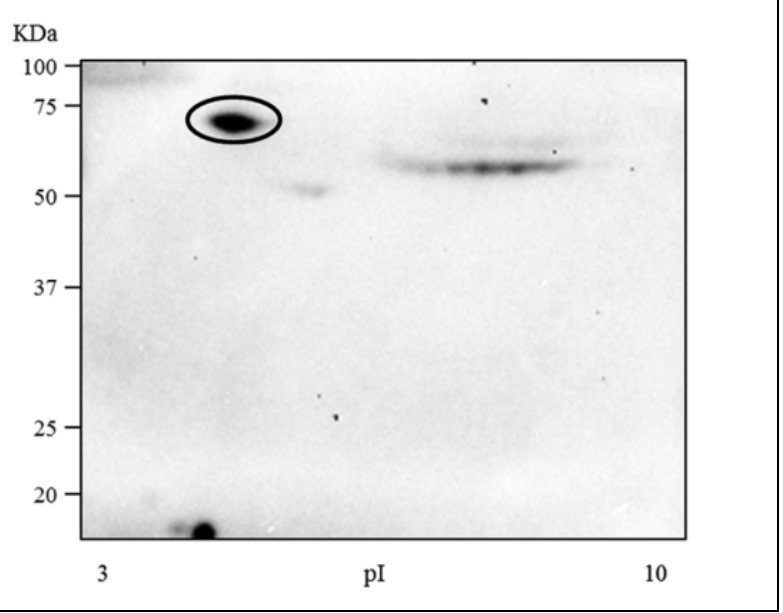

Figure 4. 2-DE WB analysis of enriched plasma sample pools from healthy controls (a), AChRAb ${ }^{+}$MG patients (b), MuSKAb ${ }^{+}$MG patients (c), and DSN MG patients (d). Circled trains of spots correspond to vitronectin. WB: Western blotting; AChRAb ${ }^{+}:$acetylcholine receptor antibody positive; MG: myasthenia gravis; 2-DE: two-dimensional electrophoresis; MuSKAb ${ }^{+}$: anti-muscle-specific kinase antibody positive.

NMJ, such as AChR and MuSK receptor. The diagnosis relies on both electrophysiology and the detection of specific autoantibodies in serum. There is a subset of clinically diagnosed myasthenic patients, referred to as DSN, who are negative for the presence of both antibodies. As MG patients subsets differ in terms of clinical characteristics, disease pathogenesis, prognosis, and response to therapies, targeted therapies should be mandatory. ${ }^{3}$ In this respect, the identification of new tissue or humoral biomarkers of MG might be of great value for both diagnosis and specific treatment.

Our aim was to identify potential plasma markers associated with the immune derangements of the different MG subtypes. To this end, we applied 2-DE coupled with MS, which allows for comparing the expression/abundance of hundreds of proteins at the same time, to identify differentially expressed plasma proteins between MG patients and healthy controls, following plasma enrichment of low- abundance protein components. To date, only few studies have dealt with identification of molecular markers in MG disease by proteomic analysis, but none of them used plasma-enriched samples to detect medium- and lowabundance proteins. ${ }^{20-22}$ By this approach, we documented a statistically significant reduction of plasma vitronectin expression in all MG patients subgroups as compared to healthy controls that did not correlate neither with the severity of the disease nor with the immunosuppressive therapy. Although it could represent a limitation of our study, vitronectin reduction in plasma of MG patients, described for the first time in this study, might be interesting and deserves further studies addressed to the evaluation of its relevance/roles in the pathogenesis or progression of MG disease.

Vitronectin, also known as serum spreading factor, is a multifunctional glycoprotein present in blood, urine, and 
amniotic fluid, ${ }^{23}$ which plays a role in the regulation of both complement and coagulation systems. ${ }^{24-26}$ It is also part of the extracellular matrix, substantially enriched at sites of injured, fibrosing, inflamed, and cancer tissues. ${ }^{27}$ In addition, it contributes to tissue remodeling and healing by regulating proteolysis, cell adhesion, migration, and survival in the injured and stressed tissue. ${ }^{28-31}$ Interestingly, significantly reduced serum vitronectin concentrations were found associated with extreme physical stress in healthy people, ${ }^{32}$ a condition comparable, in some way, to muscle fatigue in $\mathrm{MG}$, as well as with liver disease, renal disease, and systemic lupus erythematosus (SLE). ${ }^{33}$ However, the pathophysiological significance of this reduction has not been elucidated up to now, although it has been suggested that the lower levels of plasma vitronectin in chronic liver disease might be in relation to its higher levels in injured tissues undergoing healing process. ${ }^{34}$ In fact, the structure and function of vitronectin are locationdependent. ${ }^{35}$ Soluble monomers of this glycoprotein exist in plasma, and insoluble oligomers are associated with the extracellular matrix where they may interact with several cell surface receptors, including the urokinase-type plasminogen activator receptor and the $\alpha \mathrm{v}$ integrin receptor subclass. ${ }^{35}$ Conversion of vitronectin from a solutionphase to a matrix-phase protein seems to occur via interactions with plasminogen activator inhibitor-1, by which vitronectin is able to bind several partners, including complement proteins. ${ }^{35}$

The pathophysiological significance of the reduction of vitronectin in plasma of MG patients that we have documented is unknown. On account of the aforementioned findings, it could be related either to a possible deposition of vitronectin at NMJ to counteract the complement-mediated muscle damage at this level or to a corresponding variation of this glycoprotein in the muscle extracellular matrix with secondary induced alteration in clustering of AChRs at NMJ, as it occurs with variation in distribution of agrin, an extracellular heparan sulfate proteoglycan. ${ }^{36}$ Indeed, both vitronectin and agrin act on the same cells surface receptors, integrins. ${ }^{28}$

Elucidation of the underlying causes related to reduced plasma vitronectin expression could be provided by immunohistochemical analyses on patient muscle biopsies, and this surely deserve further studies.

The clinical value of measuring plasma vitronectin remains to be defined. Vitronectin is present in normal plasma at concentrations of $200-400 \mu \mathrm{g} / \mathrm{mL}^{28}$ Considered its involvement in immune defense via interaction with the terminal complex of complement, and the low expression of vitronectin in plasma of MG patients and other autoimmune diseases, such as SLE, plasma values of this glycoprotein below $200 \mu \mathrm{g} / \mathrm{mL}$ might be indicative of an impaired complement-dependent immune response.

\section{Conclusions}

By a proteomic approach on plasma samples enriched in low-abundance proteins, we evidenced a significant reduction of vitronectin expression in all MG patients subgroups compared to healthy controls, irrespective of the autoantibodies target and the severity of the disease. As it cannot allow for discriminating between the different MG clinical manifestations, it could represent a limitation of this study. Nonetheless, due to vitronectin involvement in a number of biological activities, its plasma reduction in $\mathrm{MG}$, described for the first time in our study, might be interesting and deserves further studies. In particular, the potential roles of this glycoprotein in the impaired complementdependent immune response and/or in clustering the AChRs at NMJ should be addressed.

\section{Acknowledgment}

The authors wish to thank Dr Socrates J Tzartos for support in LRP4 data, Laboratory of Molecular Neurobiology and Immunology, Department of Biochemistry, Hellenic Pasteur Institute (Athens, Greece).

\section{Declaration of Conflicting Interests}

The author(s) declared no potential conflicts of interest with respect to the research, authorship, and/or publication of this article.

\section{Funding}

The author(s) disclosed receipt of the following financial support for the research, authorship, and/or publication of this article: AJ Lepedda thanks Regione Autonoma della Sardegna for its finantial support (POR-FSE 2014-2020-Asse Prioritario 3 "Istruzione e Formazione"-Obiettivo tematico: 10, Priorità d'investimento: 10ii, Obiettivo specifico: 10.5, Azione dell'Accordo di Partenariato 10.5.12-C.U.P. J86C18000270002). The authors thank the University of Sassari for its financial support (fondo di Ateneo per la ricerca 2019).

\section{ORCID iD}

Antonio Junior Lepedda (D) https://orcid.org/0000-0002-8356894X

\section{References}

1. Drachman DB. Myasthenia gravis. New Engl J Med 1994; 330(25): 1797-1810.

2. Phillips WD and Vincent A. Pathogenesis of myasthenia gravis: update on disease types, models, and mechanisms. F1000Res 2016; 5: 1-10.

3. Gilhus NE, Skeie GO, Romi F, et al. Myasthenia gravis autoantibody characteristics and their implications for therapy. Nat Rev Neurol 2016; 12(5): 259-268.

4. Corda DG, Deiana GA, Arru G, et al. Old and novel humoral biomarkers of autoimmune myasthenia gravis. Hauppauge: Nova Science, 2018, pp. 1-194.

5. Gilhus NE, Tzartos S, Evoli A, et al. Myasthenia gravis. Nat Rev Dis Primers 2019; 5(1): 30. 
6. Drachman DB, Adams RN, Stanley EF, et al. Mechanisms of acetylcholine receptor loss in myasthenia gravis. J Neurol Neurosurg Psychiatry 1980; 43(7): 601-610.

7. Wu H, Xiong WC, and Mei L. To build a synapse: signaling pathways in neuromuscular junction assembly. Development 2010; 137(7): 1017-1033.

8. Hoch W, McConville J, Helms S, et al. Auto-antibodies to the receptor tyrosine kinase MuSK in patients with myasthenia gravis without acetylcholine receptor antibodies. Nat Med 2001; 7(3): 365-368.

9. Cole RN, Ghazanfari N, Ngo ST, et al. Patient autoantibodies deplete postsynaptic muscle-specific kinase leading to disassembly of the ACh receptor scaffold and myasthenia gravis in mice. Jpn J Physiol 2010; 588(Pt 17): 3217-3229.

10. ter Beek WP, Martinez-Martinez P, Losen M, et al. The effect of plasma from muscle-specific tyrosine kinase myasthenia patients on regenerating endplates. Am J Pathol 2009; 175(4): 1536-1544.

11. Higuchi O, Hamuro J, Motomura M, et al. Autoantibodies to low-density lipoprotein receptor-related protein 4 in myasthenia gravis. Ann Neurol 2011; 69(2): 418-422.

12. Pevzner A, Schoser B, Peters K, et al. Anti-LRP4 autoantibodies in AChR- and MuSK-antibody-negative myasthenia gravis. J Neurol 2012; 259(3): 427-435.

13. Kim N, Stiegler AL, Cameron TO, et al. Lrp4 is a receptor for Agrin and forms a complex with MuSK. Cell 2008; 135(2): 334-342.

14. Singhal N and Martin PT. Role of extracellular matrix proteins and their receptors in the development of the vertebrate neuromuscular junction. Dev Neurobiol 2011; 71(11): 982-1005.

15. Boschetti E and Righetti PG. The ProteoMiner in the proteomic arena: a non-depleting tool for discovering lowabundance species. J Proteomics 2008; 71(3): 255-264.

16. Jaretzki A 3rd, Barohn RJ, Ernstoff RM, et al. Myasthenia gravis: recommendations for clinical research standards. Task force of the medical scientific advisory board of the myasthenia gravis foundation of America. Ann Thorac Surg 2000; 70(1): 327-334.

17. Lepedda AJ, Lobina O, Rocchiccioli S, et al. Identification of differentially expressed plasma proteins in atherosclerotic patients with type 2 diabetes. J Diabetes Complicat 2016; 30(5): 880-886.

18. Lepedda AJ, Cigliano A, Cherchi GM, et al. A proteomic approach to differentiate histologically classified stable and unstable plaques from human carotid arteries. Atherosclerosis 2009; 203(1): 112-118.

19. Lepedda AJ, Nieddu G, Zinellu E, et al. Proteomic analysis of plasma-purified VLDL, LDL, and HDL fractions from atherosclerotic patients undergoing carotid endarterectomy: identification of serum amyloid A as a potential marker. Oxid Med Cell Longev 2013; 2013: 385214.

20. Cheng C, Wu G, Yeung SC, et al. Serum protein profiles in myasthenia gravis. Ann Thorac Surg 2009; 88(4): 1118-1123.
21. Wu GY, Pang JZ, Cheng C, et al. [Serum proteomics profiling for diagnosis of myasthenia gravis]. Zhonghua yi xue za zhi 2009; 89(31): 2184-2187.

22. Gomez AM, Vanheel A, Losen M, et al. Proteomic analysis of rat tibialis anterior muscles at different stages of experimental autoimmune myasthenia gravis. J Neuroimmunol. 2013; 261(1-2): 141-145.

23. Shaffer MC, Foley TP, and Barnes DW. Quantitation of spreading factor in human biologic fluids. J Lab Clin Med 1984; 103(5): 783-791.

24. Podack ER and Muller-Eberhard HJ. Isolation of human S-protein, an inhibitor of the membrane attack complex of complement. J Biol Chem 1979; 254(19): 9808-9814.

25. Podack ER, Dahlback B, and Griffin JH. Interaction of S-protein of complement with thrombin and antithrombin III during coagulation. Protection of thrombin by S-protein from antithrombin III inactivation. J Biol Chem 1986; 261(16): 7387-7392.

26. Preissner KT, Wassmuth R, and Muller-Berghaus G. Physicochemical characterization of human S-protein and its function in the blood coagulation system. Biochem $J 1985$; 231(2): 349-355.

27. Seiffert D. Constitutive and regulated expression of vitronectin. Histol Histopathol 1997; 12(3): 787-797.

28. Ekmekci OB and Ekmekci H. Vitronectin in atherosclerotic disease. Clin Chim Acta 2006; 368(1-2): 77-83.

29. Jang YC, Tsou R, Gibran NS, et al. Vitronectin deficiency is associated with increased wound fibrinolysis and decreased microvascular angiogenesis in mice. Surgery 2000; 127(6): 696-704.

30. Gu JM, Johns A, Morser J, et al. Urokinase plasminogen activator receptor promotes macrophage infiltration into the vascular wall of ApoE deficient mice. J Cell Physiol 2005; 204(1): 73-82.

31. Tsuruta Y, Park YJ, Siegal GP, et al. Involvement of vitronectin in lipopolysaccaride-induced acute lung injury. J Immunol 2007; 179(10): 7079-7086.

32. Balfoussia E, Skenderi K, Tsironi M, et al. A proteomic study of plasma protein changes under extreme physical stress. J Proteomics 2014; 98: 1-14.

33. Boyd NA, Bradwell AR, and Thompson RA. Quantitation of vitronectin in serum: evaluation of its usefulness in routine clinical practice. J Clin Pathol 1993; 46(11): 1042-1045.

34. Kobayashi J, Yamada S, and Kawasaki H. Distribution of vitronectin in plasma and liver tissue: relationship to chronic liver disease. Hepatology 1994; 20(6): 1412-1417.

35. Thurman AC. Expression and purification of the central domain from vitronectin. University of Tennessee Honors Thesis Projects, 2008, p. 10.

36. Samuel MA, Valdez G, Tapia JC, et al. Agrin and synaptic laminin are required to maintain adult neuromuscular junctions. PLOS One 2012; 7(10): e46663. 